\title{
ACEITABILIDADE DAS METODOLOGIAS ATIVAS DE ENSINO- APRENDIZAGEM ENTRE DISCENTES DE ODONTOLOGIA
}

\author{
ACEPTABILIDAD DE LAS METODOLOGÍAS ACTIVAS DE ENSEÑANZA- \\ APRENDIZAJE ENTRE ESTUDIANTES DE ODONTOLOGÍA
}

\author{
ACCEPTABILITY OF ACTIVE TEACHING-LEARNING METHODOLOGIES AMONG \\ DENTAL STUDENTS
}

\author{
Liliane Parreira Tannús GONTIJO ${ }^{1}$ \\ Álex Moreira HERVAL ${ }^{2}$ \\ Daniela Lemos CARCERERI ${ }^{3}$ \\ Sérgio Fernando Torres de FREITAS ${ }^{4}$
}

RESUMO: O estudo tem dois objetivos complementares: apresentar as Metodologias Ativas de Ensino-Aprendizagem (MAEA) aplicadas, pautadas em processos educacionais construtivistas-interacionistas, em um curso de graduação em odontologia de uma universidade federal; e analisar a aceitabilidade discente a essas metodologias. A pesquisa se constitui de estudo observacional com delimitação transversal. Vivenciaram as MAEA 175 discentes que cursaram duas disciplinas teóricas obrigatórias, sendo 91 do primeiro (ingressantes) e 84 do último ano (concluintes). Responderam ao questionário 161 discentes (92,0\%), avaliando aceitabilidade ao conteúdo da disciplina, as atividades presenciais e preparatórias, a didática do docente, a empatia discente/docente e o comprometimento discente. Identificou-se elevada aceitabilidade dos discentes às atividades andragógicas nos domínios avaliados: conteúdo teórico $(92,4 \%)$, atividades presenciais $(82,0 \%)$ e atividades preparatórias $(69,9 \%)$. Conclui-se que houve excelente aceitabilidade das metodologias ativas pelos discentes estudados, sendo maior e menos didático-dependentes entre os estudantes concluintes. Legitimou os pressupostos do paradigma educacional inovador/ativo e sua introdução desde os anos iniciais da graduação.

PALAVRAS-CHAVE: Ensino. Educação superior. Recursos humanos em odontologia. Aprendizagem baseada em problemas. Faculdades de odontologia.

RESUMEN: El estudio tiene dos objetivos complementarios: presentar las Metodologías Activas de Enseñanza-Aprendizaje (MAEA) aplicadas, pautadas en procesos educacionales

${ }^{1}$ Universidade Federal de Uberlândia (UFU), Uberlândia - MG - Brasil. Professora Associada da Área de Odontologia Preventiva e Social do Curso de Odontologia. Doutora em Saúde Pública (USP). ORCID: http://orcid.org/0000-0002-5762-1591. E-mail: lilianeg@ufu.br

${ }^{2}$ Universidade Federal de Uberlândia (UFU), Uberlândia - MG - Brasil. Professor Adjunto da Área de Odontologia Preventiva e Social do Curso de Odontologia. Doutor em Odontologia (UFMG). ORCID: https://orcid.org/0000-0001-6649-2616. E-mail: alexmherval@ufu.br

3 Universidade Federal de Santa Catarina (UFSC), Florianópolis - SC - Brasil. Professora Associada do Departamento de Odontologia. Pós-Doutorado pela Universitat de Barcelona (UB). ORCID: https://orcid.org/0000-0003-2931-7207.E-mail: daniela.lemos.carcereri@ufsc.br

${ }^{4}$ Universidade Federal de Santa Catarina (UFSC), Florianópolis - SC - Brasil. Professor Titular. Doutor em Odontologia Social (UFF). ORCID: https://orcid.org/0000-0002-8904-5998. E-mail: sergio.freitas@ufsc.br 
constructivistas-interaccionistas, en una carrera de grado en odontología de una universidad federal; y analizar la aceptabilidad discente a estas metodologías. La investigación se constituye de estudio observacional con delimitación trasversal. Vivenciaron las MAEA 175 estudiantes que cursaron dos asignaturas teóricas obligatorias, siendo 91 del primero (ingresantes) y 84 del último año (concluyentes). Contestaron al cuestionario 161 discentes (92,0\%), evaluando aceptabilidad al contenido de la asignatura, las actividades presenciales y preparatorias, la didáctica del docente, la empatía discente/docente y el comprometimiento discente. Se identificó elevada aceptabilidad de los discentes a las actividades andragógicas en los dominios evaluados: contenido teórico (92,4\%), actividades presenciales $(82,0 \%)$ y actividades preparatorias $(69,9 \%)$. Se concluye que hubo excelente aceptabilidad de las metodologías activas por los discentes estudiados, siendo mayor y menos didácticodependientes entre los estudiantes concluyentes. Legitimó los supuestos del paradigma educacional innovador/activo y su introducción desde los años iniciales de la graducación.

PALABRAS CLAVE: Enseñanza. Educación superior. Recursos humanos en odontología. Aprendizaje basada en problemas. Facultades de odontología.

ABSTRACT: The study has two complementary objectives: to present the Active TeachingLearning Methodologies (MAEA) applied, guided by constructivist-interactionist educational processes, in a odontology undergrad course of a federal university; and anylise the student acceptability and these methodologies. The research constitutes itself of an observational study with a transversal delimitation. MAEA has been experienced by 175 students who attended two mandatory theoretical disciplines, being 91 of the first (freshmen) and 84 of the last year(veterans). 161 students $(92,4 \%)$ answered the questionnaire, evaluating the discipline content acceptability, presential and preparatory activities, the professor's didactic, the student/professor empathy and the student commitment. A high student acceptability to the andragogic activities was identified in the evaluated domains: theoretical content $(92.4 \%)$, presential activities $(82.0 \%)$ and preparatory activities $(69.9 \%)$. It was concluded that there was excellent acceptability of the active methodologies by the students who participated of the research, being higher and less didactic-dependents among the veteran students. it was Legitimized the educational paradigm assumptions innovator/active and its introduction since the initial years of undergrad.

KEYWORDS: Teaching. Higher education. Human resources in odontology. Problem-based learning. Dental schools.

\section{Introdução}

Grandes e rápidas mudanças nas relações sociais têm imposto desafios para a prática andragógica no Ensino Superior (MACHADO et al., 2017) e exigido a superação da fragmentação na organização do cuidado em saúde (MARIN et al., 2010). Nesse sentido, espera-se do acadêmico o desenvolvimento de competências crítico-reflexivas, criativas, afetivas, de interação e comunicação, que são pouco trabalhadas em aulas regulares no 
modelo tradicional (ROMERAL, 2019; VERAS; FERREIRA, 2010; NASCIMENTO et al., 2013).

Neste cenário, as Metodologias Ativas de Ensino-Aprendizagem (MAEA) têm assumido uma posição de destaque, uma vez que representam estratégias inovadoras para a formação e capacitação de profissionais de saúde, de modo a instrumentalizá-los nos aspectos técnicos, éticos e políticos para a transformação de processos de trabalho na área da saúde (MARIN et al., 2010; MACHADO et al., 2017). Essas metodologias configuram-se em alternativa ao modelo tradicional de ensino-aprendizagem e fundamentam-se em uma pedagogia problematizadora, onde há estímulo para autonomia do educando, baseada na construção de competências e abordagem centrada no estudante e aprendizagem significativa (PAIVA et al., 2016; OLIVER et al., 2008). Tais mudanças das práticas andragógicas estão em constante processo de modificação e buscam formar discentes motivados a "aprender a aprender" (MITRE, 2008), formando profissionais mais ativos, reflexivos e autônomos na busca de novos conhecimentos em sua trajetória profissional.

Na área da saúde estão sendo adotadas diferentes metodologias para integrar: teoria e prática, ensino-aprendizagem, serviço e comunidade. Essas metodologias também buscam desenvolver a capacidade reflexiva acerca de problemas sociais e subsidiar o planejamento de ações criativas capazes de modificar a realidade social (REUL et al., 2016).

O perfil do Cirurgião-dentista egresso dos cursos de graduação em odontologia, com caráter generalista, humanista, crítico, reflexivo e autônomo, para atender às necessidades sociais e regulamentares, definidas pelas novas Diretrizes Curriculares Nacionais (DCNs), está alinhado a esse movimento, ao recomendar a adoção dessas estratégias para que adquiram competências suficientes considerando as características já definidas pelas diretrizes anteriores (BRASIL, 2002; BRASIL, 2018).

Experiências educacionais utilizando MAEA na Odontologia começaram a ser relatadas nas Universidades de Adelaide (Austrália, 1993) e em Harvard (EUA, 1995) (GRENWOOD et al., 1999; THAMMASITBOON et al., 2007), avançando posteriormente para outros países como: Canadá, Irlanda, Suécia, Inglaterra, Tailândia (RICH et al., 2005). No Brasil, há uma escassez de produção científica e as experiências de uso das MAEA na Odontologia se apresentam de maneira pontual e mais presentes em cursos das regiões Sul e Sudeste (MACIEL et al., 2019). Um importante desafio identificado em território nacional é a resistência de muitos docentes da área da saúde em percorrer a travessia da metodologia educacional tradicional para modelos ativos/inovadores, alegando a falta de preparação 
específica para formação nessa nova metodologia (LAZZARIN et al., 2007; DEUS et al., 2014; NORO, 2015).

As MAEA desenvolvidas no presente estudo foram pautadas em processos educacionais construtivistas-interacionistas. Assume-se as MAEA apoiadas no construtivismo ao reconhecê-lo como uma concepção teórica acerca de como o homem chega ao conhecimento, que é algo inacabado e desdobra-se em uma postura diferenciada para a sua aquisição, compondo novo paradigma de ensino (LEAO, 1999). Apesar das críticas ao construtivismo, essa teoria vem sendo repensada e reforçada, mantendo-se como base para as diretrizes educacionais nacionais (BRASIL, 2002; CHAKUR, 2015). No sentido do interacionismo, as MAEA propostas neste estudo reforçam a interação entre o sujeito que aprende de forma ativa e o objeto; o reconhecimento dos conhecimentos prévios dos discentes, a atuação dos mais experientes (pares e professores) e a contextualização e vivência no ambiente de aprendizagem são valorizados (LIMA et al., 2017).

Este estudo parte da necessidade de transição do modelo educacional tradicional (MACHADO et al., 2017) para modelos ativos/inovadores, indicados para a formação do novo perfil de egresso dos cursos de graduação na área da saúde, em especial nesse estudo no campo da Odontologia (BRASIL, 2018). Os dois objetivos complementares do presente estudo foram: apresentar as Metodologias Ativas de Ensino-Aprendizagem (MAEA) aplicadas, pautadas em processos educacionais construtivistas-interacionistas, em um curso de graduação em odontologia de uma universidade federal; e analisar a aceitabilidade discente a essas metodologias. A hipótese trabalhada foi que os discentes na fase final do curso (concluintes) têm maior aceitabilidade das metodologias ativas quando comparados aos discentes em sua fase inicial (ingressantes).

\section{Metodologia}

\section{Aspectos Éticos e Protocolo de Pesquisa}

O presente estudo seguiu critérios éticos estabelecidos para a pesquisa em seres humanos determinados em âmbitos nacional (Resolução no 466/2012 do Conselho Nacional de Saúde/Brasil) e internacional (Declaração de Helsinque). O protocolo de pesquisa foi aprovado pelo Comitê de Ética em Pesquisa da Universidade Federal de Santa Catarina (UFSC), sob número de parecer 2.651.306, CAAE: 82990718.0.0000.0121. O protocolo de 
pesquisa e a redação do artigo foram baseados no Reporting of Observational Studies in Epidemiology (STROBE).

\section{Desenho de estudo}

Desenvolveu-se um estudo observacional com delimitação transversal junto a discentes de graduação em odontologia de uma universidade federal brasileira do sul do Brasil que participaram de duas disciplinas teóricas desenvolvidas com MAEA, sendo uma do primeiro e outra do quarto ano do currículo do curso. Não se tinha a intenção de reestruturar currículo, mas aplicar e analisar o uso das MAEA em duas disciplinas, comparando a aceitabilidade de estudantes ingressantes e concluintes.

\section{Contexto de estudo e aplicação da MAEA}

O estudo foi desenvolvido na Universidade Federal de Santa Catarina, curso de Odontologia, nos anos de 2018 e 2019, em turmas regulares que possuíam entre 40 e 50 estudantes. Foram utilizadas MAEA apoiadas na linha de pensamento construtivistainteracionista, com base no método da problematização e avaliação combinada (formativa e somativa), no desenvolvimento de duas disciplinas teóricas obrigatórias do $1^{\circ}$ e $4^{\circ}$ anos.

\section{MAEA utilizadas no contexto de estudo}

Desenvolveu-se uma proposta educacional, com base nas ideias construtivistasinteracionistas, problematizadoras e afetivas, de Piaget, Vygotsky, Foucault e Freire e de seus seguidores. A proposta considera a riqueza das teorizações piagetianas em seus espaços próprios - os da Epistemologia e Psicologia, ao investigar novas formas de pensamento e a construção do conhecimento, tencionando educar homens criadores, inventores e descobridores (CHAKUR, 2015); das concepções de Freire e Vygotsky assume-se a valorização do conhecimento cotidiano (GEHLEN, et al., 2010); de Foucault repensa-se o que é normativo e pauta-se na inexistência de uma verdade absoluta e, consequentemente, na desconstrução das noções de verdadeiro/falso, certo/errado, bonito/feio (FOUCAULT, 2004); de Freire reforça-se a importância da acolhida das novas gerações e sua inserção cultural, além da abertura ao diálogo, à liberdade, participação, partilha de saberes e percepções, 
aliando os referenciais afetivos, humanos, científicos, epistemológicos e éticos (NASCIMENTO et al., 2013).

Com esses embasamentos, a proposta das MAEA implementada foi orientada por três fatores: (1) as Diretrizes Curriculares Nacionais (DCN) (BRASIL, 2002; BRASIL, 2018); (2) a concepção holística de competência (RAMOS, 2002; LIMA, 2005; TAVARES, 2018); e (3) os princípios andragógicos que estabelecem a aprendizagem com adultos pautados na motivação, nas necessidades e no respeito aos interesses; centrado na vida, na experiência e no engajamento do professor em mútua investigação com os estudantes, considerando as diferenças no estilo, tempo, lugar e ritmo de aprendizagem (KNOWLES, 1980).

O método constituído foi caracterizado ainda como problematizador, combinado e híbrido (presencial ativo e on-line), de caráter avaliativo mediador, com bases democrática e emancipatória e orientado por competência. Foram incorporadas três propostas metodológicas: a Problematização (BERBEL, 1995; FOUCAULT, 2004; VINCI, 2015; LIMA, 2017); a Aprendizagem Baseada em Problemas (ABP); e a Aprendizagem Baseada em Equipes (ABE) (MICHAELSEN, 2002; LIMA et al., 2017).

As técnicas, ferramentas e tecnologias foram constituídas de forma compartilhada com os docentes envolvidos com as disciplinas incluídas no estudo. As atividades presenciais e as atividades preparatórias (extra sala) foram planejadas a partir do conteúdo definido no currículo do curso de graduação em odontologia da universidade e foram promovidas adaptações de conteúdo e abordagem andragógica, para despertar o discente para os métodos ativos utilizados. As atividades extra-sala, consideradas de estudo, leitura e preparação, foram previstas de forma suplementar à carga horária da disciplina.

Foram utilizados como disparadores de aprendizagem: as narrativas de práticas, entrevistas, artigos, capítulos de livro, os documentos oficiais do Ministério da Saúde, as legislações (leis, normas e resoluções), programas de entrevista, os curtas metragens (com duração de até 30min) e longas metragens (com duração mínima de 70 minutos), construção de painéis temáticos, análise de experiências, situações-problema, problematização de casos simulados e reais, plenárias, visitas técnicas aos setores internos e em organizações e equipamentos sociais externos à instituição de ensino superior.

$\mathrm{Na}$ lógica da aprendizagem cooperativa, foram estruturados quatro a cinco grupos (comunidades de aprendizagem), que contabilizaram o mínimo de 5 e máximo de 10 estudantes, de acordo com o número de matriculados nas disciplinas. As comunidades de aprendizagem foram sugeridas pelos mediadores e organizadas pelos próprios estudantes, mediante afinidades entre os mesmos. As ações andragógicas exigiam contatos e convivência

RIAEE - Revista Ibero-Americana de Estudos em Educação, Araraquara, v. 15, n. 4, p. 2023-2048, out./dez. 2020. e-ISSN: 1982-5587. 
frequentes e trabalho em equipe, de forma colaborativa, autônoma, respeitosa e produtiva. As atividades, presenciais e preparatórias, foram orientadas por consignas disponibilizadas pelo aplicativo Whatsapp ${ }^{\circledR}$. As consignas têm um papel importante na comunicação da informação, clara, completa e afirmativa, no sentido de orientar o desenvolvimento das atividades, presenciais ou preparatórias, pelos estudantes. São geralmente elaboradas combinando texto e imagens associadas e representativas do tema e contexto referido.

No componente interativo on-line, houve predomínio do uso de Whatsapp ${ }^{\circledR}$ para efetivar orientações, aproximar o contato entre professor-estudante e realizar trocas de mensagens (dúvidas, questionamentos e compartilhamentos). MARTINS et al. (2018) analisaram que o uso de dispositivos móveis na sala de aula vem ao encontro do perfil dos estudantes de ensino superior na contemporaneidade, destacando-se a necessidade de (re)construção das práticas andragógicas diante desse alunado. Utilizou-se, também, na comunicação complementar para a interação docente/discente, a plataforma moodle na disponibilização dos temas programáticos, referências literárias e digitais, artigos e conceitos de avaliação distribuídos durante o semestre letivo.

\section{Participantes do estudo}

A amostragem do estudo foi intencional, incluindo os estudantes que cursaram uma disciplina do primeiro (ingressantes) e do quarto ano (concluintes) do curso, durante o segundo semestre de 2018 e primeiro semestre de 2019. O universo de discentes que cursaram essas disciplinas no período do estudo foi de 175, sendo 91 ingressantes e 84 concluintes.

Participaram seis docentes na aplicação do método em sala de aula. Destes, dois eram coordenadores das mencionadas disciplinas e integraram a preparação metodológica vivencial, isto é, capacitação com carga horária de 180 horas em MAEA, etapa recomendada e antecedente à aplicação do método, junto aos estudantes. Os demais professores aceitaram participar do estudo e desenvolver suas ferramentas e estratégias durante o seu desenvolvimento. Houve o apoio e orientação da pesquisadora, especialista em MAEA, que participou, ativa e presencialmente, em sala de aula, durante o planejamento, execução e avaliação do ato andragógico, acompanhando e realizando ajustes que se fizeram necessários. 


\section{Mensuração dos dados}

Os dados foram coletados por meio de questionário estruturado desenvolvido pelos pesquisadores, composto por seis questões divididas em dois grupos com respostas do tipo Likert. No primeiro grupo de questões os discentes avaliaram a contribuição da disciplina para a formação profissional considerando os domínios conteúdo teórico, as atividades andragógicas desenvolvidas nas aulas presenciais e as atividades e tarefas desenvolvidas extra-sala (preparatórias). No segundo grupo de questões os discentes avaliaram o desempenho docente relativo à didática com as MAEA, ao relacionamento com os estudantes (empatia), e o comprometimento discente que constou de autoavaliação, quanto à participação discente nas atividades presenciais e preparatórias.

\section{Análise dos dados}

Os dados foram tabulados e analisados por meio do Software IBM SPSS Statistics ${ }^{\circledR}$ versão 21. As respostas ao primeiro grupo de questões foram dicotomizadas em avaliação positiva ("concordo plenamente" e "concordo parcialmente") e avaliação negativa ("discordo plenamente" e "discordo parcialmente"). As respostas do segundo grupo de questões foram dicotomizadas em alto desempenho ("bom" e "muito bom") e baixo desempenho ("regular" e "insuficiente"). As respostas "não sei opinar" foram descartadas nos dois grupos de questões, pois não indicavam nenhum dos dois polos de respostas consideradas.

Inicialmente procedeu-se à exploração dos dados e análise descritiva. Em seguida foi testada a associação entre as respostas obtidas dos estudantes, para todas as variáveis coletadas, e a etapa do curso (ingressantes e concluintes) por meio do teste Qui-quadrado. Em seguida, testou-se a associação entre domínios conhecimento teórico, atividades andragógicas e atividades preparatórias com a didática do docente, com o relacionamento com os estudantes e o comprometimento discente (autoavaliação da participação e envolvimento na disciplina) considerando as duas etapas do curso, por meio do teste Qui-quadrado ou Teste Exato de Fischer, quando necessário. Em todas as análises bivariadas foi considerado o valor de significância menor que $5 \%(\mathrm{p}<0,05)$. 


\section{Resultados}

Dos 175 estudantes regularmente matriculados e que vivenciaram as MAEA em duas disciplinas obrigatórias do curso de odontologia, responderam ao questionário 161 discentes, o que correspondeu a uma taxa de participação da pesquisa de 92,00\%. No ano de 2018 participaram 32 ingressantes (19,90\%) e 30 concluintes (18,60\%). Em 2019 participaram 45 ingressantes $(33,50 \%)$ e 54 concluintes $(28,00 \%)$. A avaliação positiva prevaleceu em todas os domínios avaliados: conteúdo teórico $(n=145 ; 92,4 \%)$, atividades presenciais $(n=123 ; 82 \%)$ e atividade preparatórias $(n=102 ; 69,9 \%)$. Foi observado ainda um elevado nível de comprometimento dos discentes $(n=132 ; 82,0 \%)$. Os dados descritivos das variáveis analisadas estão apresentados na Tabela 1 .

Tabela 1 - Distribuição dos discentes segundo as variáveis analisadas

\begin{tabular}{|c|c|c|}
\hline & \multicolumn{2}{|c|}{$\begin{array}{c}\text { Discentes do Curso de } \\
\text { Odontologia }\end{array}$} \\
\hline & $\mathbf{N}$ & $\%$ \\
\hline \multicolumn{3}{|l|}{ Ano avaliado $(\mathrm{N}=161)$} \\
\hline 2018 & 62 & 38,5 \\
\hline 2019 & 99 & 61,5 \\
\hline \multicolumn{3}{|c|}{ Disciplina cursada $(\mathrm{N}=161)$} \\
\hline Concluintes & 77 & 47,8 \\
\hline Ingressantes & 84 & 52,2 \\
\hline \multicolumn{3}{|c|}{ O conteúdo teórico contribuiu para a minha formação $(\mathrm{N}=157)$} \\
\hline Avaliação negativa & 12 & 7,6 \\
\hline Avaliação positiva & 145 & 92,4 \\
\hline \multicolumn{3}{|c|}{ As atividades presenciais (aulas teóricas) contribuíram para a minha formação $(\mathrm{N}=150)$} \\
\hline Avaliação negativa & 27 & 18,0 \\
\hline Avaliação positiva & 123 & 82,0 \\
\hline \multicolumn{3}{|c|}{ As atividades preparatórias (extraclasse) contribuíram para a minha formação $(N=146)$} \\
\hline Avaliação negativa & 44 & 30,1 \\
\hline Avaliação positiva & 102 & 69,9 \\
\hline \multicolumn{3}{|c|}{ Avaliação da didática do docente $(\mathrm{N}=161)$} \\
\hline Baixo desempenho & 36 & 22,4 \\
\hline Alto desempenho & 125 & 77,6 \\
\hline \multicolumn{3}{|c|}{ Avaliação do relacionamento docente com o discente (empatia) $(\mathrm{N}=161)$} \\
\hline Baixo desempenho & 15 & 9,3 \\
\hline Alto desempenho & 146 & 90,7 \\
\hline \multicolumn{3}{|c|}{ Autoavaliação sobre a participação e o envolvimento na disciplina ( $\mathbf{N}=153)$} \\
\hline Não comprometimento & 21 & 12,9 \\
\hline Comprometimento & 132 & 82,0 \\
\hline
\end{tabular}

$\mathrm{N}=$ Número de discentes respondentes; $\%=$ porcentagem.

Fonte: elaborada pelos autores 
A Tabela 2 apresenta as respostas obtidas na segmentação dos discentes quanto à etapa do curso de graduação. Os discentes concluintes apresentaram maior aceitabilidade nas dimensões aulas presenciais $(\mathrm{p}=0,021)$, atividades preparatórias $(\mathrm{p}=0,001)$, didática docente $(p<0,001)$ e relacionamento entre discente e docente $(0,008)$.

Tabela 2 - Análise da associação das variáveis em estudo com a etapa/disciplina do curso em que os discentes estão inseridos

\begin{tabular}{|c|c|c|c|c|c|c|c|}
\hline & \multicolumn{2}{|c|}{ Ingressantes } & \multicolumn{2}{|c|}{ Concluintes } & \multirow{2}{*}{$\mathrm{X}^{2}$} & \multirow{2}{*}{ Valor p } & \multirow{2}{*}{$\begin{array}{c}\text { Maior } \\
\text { aceitabilidade }\end{array}$} \\
\hline & $\mathbf{N}$ & $\%$ & $\mathbf{N}$ & $\%$ & & & \\
\hline \multicolumn{8}{|c|}{ O conteúdo teórico contribuiu para a minha formação } \\
\hline Avaliação Negativa & 9 & 14,3 & 3 & 5,2 & \multirow{2}{*}{1,92} & \multirow{2}{*}{0,165} & \multirow{2}{*}{$\begin{array}{l}\text { Não houve } \\
\text { associação }\end{array}$} \\
\hline Avaliação Positiva & 72 & 85,7 & 73 & 94,8 & & & \\
\hline \multicolumn{8}{|c|}{ As atividades aulas presenciais contribuíram para a minha formação } \\
\hline Avaliação Negativa & 19 & 32,5 & 8 & 12,3 & \multirow{2}{*}{5,29} & \multirow{2}{*}{0,021} & \multirow{2}{*}{ Concluintes } \\
\hline Avaliação Positiva & 56 & 67,5 & 66 & 87,7 & & & \\
\hline \multicolumn{8}{|c|}{ As atividades preparatórias contribuíram para a minha formação } \\
\hline Avaliação Negativa & 33 & 50,0 & 11 & 22,1 & \multirow{2}{*}{10,4} & \multirow{2}{*}{0,001} & \multirow{2}{*}{ Concluintes } \\
\hline Avaliação Positiva & 52 & 50,0 & 60 & 77,9 & & & \\
\hline \multicolumn{8}{|c|}{ Avaliação da didática do docente } \\
\hline Baixo desempenho & 29 & 35,7 & 6 & 7,8 & \multirow{2}{*}{17,2} & \multirow{2}{*}{$<0,001$} & \multirow{2}{*}{ Concluintes } \\
\hline Alto desempenho & 54 & 64,3 & 71 & 92,2 & & & \\
\hline \multicolumn{8}{|c|}{ Avaliação do relacionamento do docente com os discentes } \\
\hline Baixo desempenho & 14 & 16,7 & 1 & 1,3 & \multirow{2}{*}{11,2} & \multirow{2}{*}{0,008} & \multirow{2}{*}{ Concluintes } \\
\hline Alto desempenho & 60 & 83,3 & 76 & 98,7 & & & \\
\hline \multicolumn{8}{|c|}{ Autoavaliação sobre a participação e o envolvimento na disciplina } \\
\hline Baixo desempenho & 13 & 23,8 & 8 & 11,2 & \multirow{2}{*}{0,65} & \multirow{2}{*}{0,416} & \multirow{2}{*}{$\begin{array}{l}\text { Não houve } \\
\text { associação }\end{array}$} \\
\hline Alto desempenho & 67 & 76,2 & 68 & 88,3 & & & \\
\hline
\end{tabular}

$\mathrm{N}=$ Número de discentes; $\%=$ porcentagem; $\mathrm{X}^{2}=$ Teste Qui-quadrado; $\mathrm{p}<0,05$

Fonte: elaborada pelos autores

A Tabela 3 apresenta a associação entre a desempenho da didática do docente aferido com os dois grupos de discentes (ingressantes e concluintes) e a percepção sobre a contribuição para a formação (conteúdo teórico, aulas presenciais e atividades preparatórias). Foram aferidas associações estatisticamente significativas apenas para as aferições dos ingressantes, as quais indicam que quanto menor a mensuração da didática do docente por parte dos estudantes, menor a assimilação do conteúdo teórico $\left(\mathrm{X}^{2}=6,89\right)$, menor a aceitabilidade das atividades presenciais $\left(X^{2}=9,43\right)$ e menor a aceitabilidade das atividades preparatórias $\left(\mathrm{X}^{2}=15,48\right)$. 
Tabela 3 - Análise da associação entre a didática docente e a percepção discente sobre a contribuição para sua formação, frente aos aspectos MAEA (conteúdo teórico; Atividades Presenciais; e Atividades Preparatórias) e à etapa do curso de graduação

\begin{tabular}{|c|c|c|c|c|c|c|}
\hline & \multicolumn{6}{|c|}{ Desempenho do docente quando à didática } \\
\hline & \multicolumn{3}{|c|}{ Ingressantes } & \multicolumn{3}{|c|}{ Concluintes } \\
\hline & $\begin{array}{l}\text { Baixo } \\
\text { N (\%) }\end{array}$ & $\begin{array}{c}\text { Alto } \\
\text { N (\%) }\end{array}$ & $\begin{array}{c}\text { Valor de } \\
\text { p }\end{array}$ & $\begin{array}{l}\text { Baixo } \\
N(\%)\end{array}$ & $\begin{array}{c}\text { Alto } \\
\text { N (\%) }\end{array}$ & $\begin{array}{c}\text { Valor de } \\
\text { p }\end{array}$ \\
\hline \multicolumn{7}{|c|}{ O conteúdo teórico contribuiu para a minha formação } \\
\hline Avaliação Negativa & $7(11,1)$ & $2(3,2)$ & \multirow{2}{*}{0,008} & $1(1,3)$ & $2(2,6)$ & \multirow{2}{*}{0,565} \\
\hline Avaliação Positiva & $2(3,2)$ & $52(82,5)$ & & $5(6,6)$ & $68(89,5)$ & \\
\hline \multicolumn{7}{|c|}{ As atividades aulas presenciais contribuíram para a minha formação } \\
\hline Avaliação Negativa & $12(15,8)$ & $7(9,2)$ & \multirow{2}{*}{0,002} & $2(2,7)$ & $6(8,1)$ & \multirow{2}{*}{0,152} \\
\hline Avaliação Positiva & $14(18,4)$ & $43(56,6)$ & & $3(4,1)$ & $63(85,1)$ & \\
\hline \multicolumn{7}{|c|}{ As atividades preparatórias contribuíram para a minha formação } \\
\hline Avaliação Negativa & $20(26,7)$ & $13(17,3)$ & \multirow{2}{*}{0,001} & $1(1,4)$ & $10(14,1)$ & \multirow{2}{*}{0,724} \\
\hline Avaliação Positiva & $7(9,3)$ & $35(46,7)$ & & $4(5,6)$ & $56(78,9)$ & \\
\hline
\end{tabular}

$\mathrm{N}=$ Número de discentes; \%= porcentagem; (a) Teste Qui-quadrado; (b) Teste Exato de Fisher; $\mathrm{p}<0,05$ Fonte: elaborada pelos autores

A Tabela 4 apresenta a associação entre a desempenho do relacionamento docente e discente aferido com os dois grupos de discentes (ingressantes e concluintes) e a percepção sobre a contribuição para a formação (conteúdo teórico, aulas presenciais e atividades preparatórias). Os testes estatísticos mostraram que não houve associação estatística entre o relacionamento discente e docente e a percepção da contribuição das MAEA para a formação discente em qualquer um dos domínios avaliados, seja no início ou no final do curso. 
Tabela 4 - Análise da associação entre o relacionamento com docente (empatia), a percepção sobre a contribuição para a formação e a etapa do curso de graduação

\section{Desempenho do relacionamento entre docente e discente}

\begin{tabular}{|c|c|c|c|c|c|c|}
\hline & \multicolumn{3}{|c|}{ Ingressantes } & \multicolumn{3}{|c|}{ Concluintes } \\
\hline & Baixo & Alto & Valor de & Baixo & Alto & Valor de \\
\hline & $\mathrm{N}(\%)$ & $\mathrm{N}(\%)$ & $\mathbf{p}$ & $\mathrm{N}(\%)$ & $\mathrm{N}(\%)$ & $\mathbf{p}$ \\
\hline \multicolumn{7}{|c|}{ O conteúdo teórico contribuiu para a minha formação } \\
\hline Avaliação Negativa & $1(1,2)$ & $8(9,9)$ & \multirow{2}{*}{$0,666(a)$} & $0(0,0)$ & $1(1,4)$ & \multirow{2}{*}{$1,000(b)$} \\
\hline Avaliação Positiva & $12(14,8)$ & $60(74,1)$ & & $1(1,4)$ & $72(97,2)$ & \\
\hline
\end{tabular}

As atividades aulas presenciais contribuíram para a minha formação

\begin{tabular}{lcccccc} 
Avaliação Negativa & $5(5,6)$ & $14(18,4)$ & $0,379(a)$ & $0(0,0)$ & $8(10,8)$ & $1,000(b)$ \\
Avaliação Positiva & $8(10,5)$ & $49(64,5)$ & & $1(1,4)$ & $65(87,8)$ & \\
\hline
\end{tabular}

As atividades preparatórias contribuíram para a minha formação

\begin{tabular}{lccllll} 
Avaliação Negativa & $8(10,7)$ & $25(33,3)$ & $0,090(a)$ & $0(0,0)$ & $11(15,5)$ & 1 \\
Avaliação Positiva & $4(5,3)$ & $38(50,7)$ & & $0(0,0)$ & $60(84,5)$ & $1,000(b)$ \\
\hline
\end{tabular}

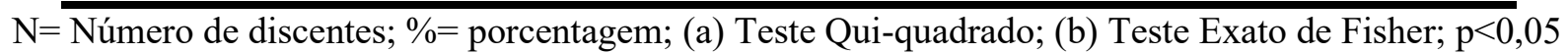
Fonte: elaborada pelos autores

\section{Discussão}

Ao aplicar e analisar o uso das MAEA, verificando a aceitabilidade dos discentes ingressantes e concluintes, frente às disciplinas desenvolvidas no curso de graduação em Odontologia de universidade federal no sul do Brasil, este estudo identificou uma elevada aceitação da metodologia proposta em todos os domínios avaliados (conteúdo teórico, atividades presenciais e atividades preparatórias). Foi possível confirmar a hipótese de que estudantes com maior maturidade acadêmica (concluintes) tem maior aceitação ao uso de metodologias ativas.

Ao analisar a influência do docente na aplicação das metodologias ativas de ensinoaprendizagem, foi possível compreender que a menor mensuração da didática do docente por parte do estudante influenciou na aceitabilidade da MAEA pelos ingressantes. Já o relacionamento entre docente e discente não mostrou uma interferência estatisticamente significativa para nenhum dos grupos de estudantes investigados.

Apesar de existirem estudos que demonstram uma preferência dos estudantes de graduação para métodos tradicionais centrados no docente (DEUS et al., 2014), a aceitabilidade das MAEA vem sendo identificada em algumas experiências nos cursos de 
graduação em Odontologia no Brasil, desmistificando a ideia da dificuldade de sua aceitação discente (PIRES; BUENO, 2006; CARVALHO et al., 2016; GONÇALVES, et al., 2018; SARAIVA et al., 2018; REUL et al., 2016; SILVA et al., 2020). Cabe ressaltar que essas experiências utilizaram em grande parte a metodologia da Problematização (PIRES; BUENO, 2006; CARVALHO et al., 2016; SARAIVA et al., 2018; REUL et al., 2016; SILVA et al., 2020). A aceitabilidade das MAEA em comparação aos métodos tradicionais também é observada em estudos internacionais, usualmente a ABP (BAEPLER; WALKER; DRIESSEN， 2014; O'FLAHERTY; PHILLIPS， 2015; GILBOY; HEINERICHS; PAZZAGLIA, 2015; HUNG, 2015). Tanto a Problematização como a ABP são modalidades que auxiliam a superar o modelo tradicional de ensino em favor de uma forma de ensinoaprendizagem que considera a complexidade com que a realidade se apresenta (MARIN et al., 2010).

Autores que defendem o uso das MAEA em cursos de graduação em Odontologia identificaram diversas vantagens dessa metodologia nos resultados de seus estudos (SARAIVA et al., 2018; REUL et al., 2016; SILVA et al., 2020). Saraiva et al. (2018) e Silva et al. (2020) apontaram que as MAEA favorecem o trabalho em equipe, uma vez que estimulam práticas colaborativas interprofissionais. Reul et al. (2016) perceberam que as MAEA despertam no discente o interesse para o pensar, questionar, aprender a aprender e assumir seu papel como futuro transformador da realidade social. Para Silva et al. (2020), as MAEA estimularam o protagonismo, a criatividade e autonomia dos estudantes envolvendo dimensões cognitivas, comunicacionais, estéticas e sociais. Freitas et al. (2009), Mesquita (2016) e Silva et al. (2020) afirmam que essas metodologias têm papel relevante ao fazer com que os discentes assumam o compromisso de intervir sobre as necessidades sociais.

Alguns elementos são apontados para garantir uma maior aceitabilidade das MAEA: a capacitação prévia dos docentes para o uso das novas metodologias (DEUS et al., 2014; GUIMARÃES et al., 2016), a garantia de um tempo mínimo de três anos para consolidar as práticas pedagógicas propostas (DEUS et al., 2014), o direcionamento das MAEA para os estágios na rede de saúde (CARVALHO et al., 2016; REUL et al., 2016), uma constante revisão e reflexão crítica sobre os processos utilizados (MARIN et al., 2010) e desencadear novas 'trans-forma-ações' docentes, mediante novas lentes de interpretação referentes aos desafios e possíveis caminhos (COSTA; VIEIRA, 2018).

Dentre esses aspectos, os resultados deste estudo ressaltaram a importância da didática do docente na aceitabilidade das MAEA. Destaca-se, também, o fato dos professores responsáveis pelas disciplinas terem realizado o curso preparatório sobre as MAEA antes de 
adotarem o método em sala de aula, bem como da educação permanente desenvolvida durante o decorrer do estudo (contato semanal e reuniões de avaliação crítico-reflexivas com a pesquisadora responsável).

Diversos fatores podem estar relacionados com a capacidade do docente para aplicar as metodologias ativas. Tais fatores incluem a resistência do docente e dificuldade de compreensão da aplicabilidade das MAEA (MESQUISTA, 2016; ROMERAL, 2019); as experiências acadêmicas e profissionais dos docentes, visto que docentes mais jovens são mais receptivos e motivados às mudanças (NAGIB, 2018; OLIVEIRA et al., 2018); a falta de investimentos efetivos na formação e desenvolvimento docente (NAGIB, 2018; ALVES; MACHADO, 2018); e a exigência de um maior esforço e dedicação para o planejamento das aulas e atividades (GUIMARÃES et al., 2016). É importante ressaltar que, além da formação adequada dos docentes, uma reestruturação curricular tem sido apontada como elemento fundamental para o desenvolvimento das MAEA nos cursos de graduação (MESQUITA, 2016; ALVES; MACHADO, 2018).

Os resultados deste estudo demonstraram que o grupo de ingressantes foi mais didático-dependente que o grupo de concluintes, este último se mostrou menos dependente deste aspecto. A menor dependência da didática pelos concluintes pode estar relacionada ao fato de que no último ano dos cursos graduação há uma maior concentração de estágios e proximidade com a vida profissional (IGUE; BARIANI; MILANESI, 2008); além de ser um momento em que o discente apresenta maior amadurecimento acadêmico, quando aglutina uma série de competências e habilidades para o aprendizado (MANABE et al., 2014). Quanto ao grupo de ingressantes, observa-se que são recém-saídos do ensino médio (normalmente de um modelo tradicional de aprendizagem), diferem seus hábitos de estudo, em aspectos diversos, dos necessários para uma melhor adaptação no contexto universitário (IGUE; BARIANI; MILANESI, 2008; MANABE et al., 2014).

Outros elementos ajudam a compreender este resultado: as expectativas iniciais dos estudantes mais realistas sobre o seu envolvimento curricular indicaram melhor desempenho acadêmico (GOMES; SOARES, 2013; POLYDORO, 2000); experiências prévias do acadêmico, inclusive com estes métodos (NAGIB, 2018); o desempenho dos estudantes na participação e dedicação as atividades acadêmicas (GOMES; SOARES, 2013); apreensão das ferramentas de busca do conhecimento e interesse discente em aprender (COSTA; ARAÚJO; ALMEIDA, 2016; IGUE; BARIANI; MILANESI, 2008); desenvolvimento das capacidades cognitivas promotoras do raciocínio integrado (ROCHA et al., 2016).

RIAEE - Revista Ibero-Americana de Estudos em Educação, Araraquara, v. 15, n. 4, p. 2023-2048, out./dez. 2020. e-ISSN: 1982-5587. 
Apesar do maior desafio com os ingressantes, as MAEA devem ser introduzidas desde o início da graduação, visando instituir um modelo autônomo de aprendizagem discente (RONDON; MACIEL, 2018), possibilitar a transição paradigmática da abordagem tradicional para a ativa (TORRES; SAMPAIO; CALDEIRA, 2019) e se alinhar a um momento de mudanças na vida pessoal do discente (SOUZA; LOURENÇO; SANTOS, 2016). Experiências de aprendizagens enriquecedoras têm sido relatadas com a introdução de MAEA no primeiro ano da graduação, tanto para os acadêmicos como para os professores, apoiadas no debate temático aprofundado de assuntos polêmicos e compartilhamento de percepções, dificilmente alcançados em aula habitual de metodologia tradicional (RODRIGUES; CALDAS, 2018; CARVALHO, 2018).

Por parte do docente, o uso das MAEA junto aos ingressantes exigirá maior empenho, pois apresentam estratégias distintas para lidar com as dificuldades da inserção na vida acadêmica, bem como a diferente percepção dos discentes sobre as situações vividas (SOUZA; LOURENCO; SANTOS, 2016). Além disso, independentemente do momento em que as MAEA são inseridas, os docentes devem reconhecer que serão necessários um maior apoio psicoandragógico, presença mais significativa, segurança em inovar e perfil amoroso e dedicado na condução discente da travessia educacional durante os primeiros seis meses (LIMA, 2013). Qualquer que seja o método adotado, o docente é norte, guia, modelo, figura de referência e espelho, que refletirá em várias dimensões do futuro discente (SILVA, et al., 2007; SILVA et al., 2016).

Embora a maior ou menor empatia entre discentes e docentes não tenha alterado a percepção dos primeiros sobre seu desempenho, seja nos ingressantes seja nos concluintes, cabe destacar que a aplicação das MAEA exige uma postura diferenciada por parte dos envolvidos. A nova postura do docente decorre da responsabilidade que esse ator tem sobre a formação de pessoas capazes de evoluir, refletir e de aprenderem com as experiências (DOHMS et al., 2012; PERRENOUD, 2002), e da necessidade de criar um espaço democrático para o desenvolvimento do discente (SILVA et al., 2016). O docente deve assumir uma postura de apoiador, garantindo segurança e amorosidade para a inovação e condução do discente na travessia educacional (LIMA, 2013; SILVA et al., 2007; SILVA et al., 2016).

Por sua vez, a nova postura do discente decorre da introdução em uma nova cultura da aprendizagem, em que deve haver um interesse em aprender de forma útil para a vida (POZO, 2002; SILVA et al., 2016). O discente necessita saber pensar para intervir na realidade, de forma inclusiva e democrática, e exercitar o respeito mútuo e o diálogo, para que não haja 
espaço para imposições ou limitações na sua constituição como cidadão autônomo, crítico e ético, possível pelo manejo adequado da educação nos seus aspectos formais e políticos (CRUZ; PEREIRA, 2013; PIZZI, 2014).

Nessa nova cultura relacional exige-se uma postura afetiva (RAMOS, 2011; NASCIMENTO et al., 2013; VERAS; FERREIRA, 2010) que se opõe à tradicional segmentação das dimensões afetiva e cognitiva, com maior valorização da última (VERAS; FERREIRA, 2010; NASCIMENTO et al., 2013). Essa postura afetiva exige que sejam criadas uma cumplicidade e reciprocidade, com a tomada de decisão a partir da postura não-verbal do discente e do estímulo ao estudo, ao diálogo, à reflexão, reconhecer e agir contra a violência (ora sutil, ora mais evidente), mostrar caminhos do diálogo, posicionamentos simétricos e, principalmente, interativamente investir nas referidas relações entre docentes e discentes. (LEITE, 2004; SILVA, et al., 2016; CRUZ; PEREIRA, 2013; AQUINO, 1998; CHAUÍ, 2001).

Destaca-se a compreensão do aspecto da reciprocidade entre os perfis adotados: ao perfil de docente autoritário associa-se um discente dependente; ao docente investigativo, um discente interessado; ao docente mediador, um discente engajado; e, por fim, a um docente orientador, um discente autônomo (TOMAZINHO, 2018).

Os resultados deste estudo não estão isentos de limitações. Primeiramente, é preciso destacar que, sendo um estudo transversal onde não foram coletadas variáveis de confundimento, não é possível estabelecer uma clara relação de causalidade. Essa limitação não impede que os resultados sirvam para subsidiar o planejamento, inclusão e aprimoramento das MAEA em cursos de graduação. Outra limitação do estudo está na seleção dos participantes. Apesar de buscar incluir todos os estudantes que vivenciaram as MAEA no curso em questão e ter uma elevada taxa de resposta, a inclusão dos discentes se deu de forma intencional e não probabilística.

Este estudo analisa a experiência com MAEA aplicadas isoladamente em duas disciplinas de um curso de graduação em Odontologia, motivadas por interesses de pesquisa dos docentes e não de reforma curricular institucional. A aplicação de inovações pedagógicas no campo da Odontologia ainda é incipiente (MACIEL et al., 2019). Dificuldades como o pouco financiamento destinado a pesquisas com esta temática e a falta de apoio e estímulo à adoção de MAEA da instituição formadora, em especial na esfera pública, inviabilizam transformações na educação (MACIEL et al., 2019; DEUS et al., 2014), obrigando o professor a adaptar as referidas metodologias aos recursos disponíveis na sua realidade de trabalho, hegemônica no método tradicional (MACIEL et al., 2019; LAZZARIN et al., 2007; 
NORO, 2015). Apesar dessa baixa valorização de uma nova prática andragógica, há uma urgência na implementação da aprendizagem ativa, centrada no estudante e problemas reais, para formar profissionais adequados às necessidades de saúde da população e do Sistema Único de Saúde (SUS), (FREITAS et al., 2009). No Brasil, as mudanças na educação são possíveis, mas requerem um longo período de imersão em práticas ativas de aprendizagem. (PASSOS; VIEIRA; COSTA, 2018).

\section{Conclusão}

Este estudo mostrou elevada aceitabilidade das MAEA, sendo maior e menos didáticodependente entre discentes concluintes do curso de graduação em Odontologia na instituição estudada. Como implicações para a prática, este estudo aponta três aspectos importantes.

Necessidade de maior preparação metodológica dos docentes, tanto para aplicação das MAEA e domínio do conteúdo, quanto de aspectos atitudinais (motivação, segurança e afetividade).

Discentes em fases mais avançadas do curso participam mais ativamente, otimizando os recursos de aprendizagem e propiciando maior integração entre os acadêmicos.

A possibilidade de introdução das MAEA nas fases iniciais da graduação, em turmas regulares de 40 a 50 estudantes, com maior atenção à dependência didática dos estudantes ingressantes, demandando mais dos docentes para aceitar a aplicação das MAEA.

Ressalta-se dois fatores imprescindíveis para consolidação das MAEA: a preparação docente e o envolvimento discente. Considera-se estes dois fatores imperiosos para as mudanças fundamentadas na compreensão da adoção de linha de pensamento andragógico inovador, em detrimento de conjunto de ferramentas aplicadas de forma isolada, além da necessidade de tempo e estratégias contemporâneas, ajustes e aperfeiçoamentos, em contraposição ao modelo tradicional soberano.

Estudos com outros desenhos metodológicos, em especial ensaios de campo e longitudinais, contendo amostras mais significativas, devem ser realizados para complementar as informações e aumentar o nível de evidência do estudo. Outras pesquisas são necessárias, ainda, para verificar o desempenho de docentes e discentes nas MAEA.

A excelente aceitabilidade discente às MAEA observada nesse estudo legitima os pressupostos do paradigma educacional inovador: a educação problematizadora; o desenvolvimento das capacidades crítica, reflexiva, autônoma e transformadora do educando; e seus componentes construtivistas-interacionistas, colaborativos, interdisciplinares, 
contextualizados, investigativos, motivadores e humanistas. Estes elementos fundantes das MAEA estão em sintonia com as novas Diretrizes Curriculares Nacionais em saúde, reunindo elementos reveladores de uma formação discente que experienciou aprendizagem significativa, dínamo de profissionais comprometidos com o mundo do trabalho e das necessidades da população e decorrente transformação da realidade social.

AGRADECIMENTOS: Agradecemos aos discentes por participarem do método e responderem ao questionário; às docentes, Profa. Dra. Alessandra Rodrigues de Camargo e Profa. M.a. Ana Maria Hecke Alves, pela participação na preparação docente e aplicação do método ativo; aos docentes, Profa Dra. Ana Lúcia Schaefer Ferreira de Mello, Profa M.a. Fernanda Marcello Scotti, Profa Dra. Luisa Machado Barin e Prof. M.e. Ricardo de Souza Vieira, por colaborarem na aplicação do método ativo nas disciplinas do Curso de Graduação em Odontologia; e ao apoio das Gestões (2018-2019) do Departamento de Odontologia e do Programa de Pós-Graduação em Saúde Coletiva da Universidade Federal de Santa Catarina PPGSC/UFSC, em Florianópolis, que juntos tornaram possível, em diferentes dimensões, este estudo.

\section{REFERÊNCIAS}

ALTURE VÍDEOS. Congresso Paulo Tomazinho: implantação de estratégias de metodologias ativas e adoção por professores e engajamento dos alunos. $1^{\circ}$ Congresso Brasileiro online de Metodologias Ativas. Alture Vídeos, 2018. 1 vídeo (49 min.). Disponível em: https://www.youtube.com/watch?v=OTQOBXq4B7A. Acesso em: 22 abr. 2020.

ALVES, R. de S.; MACHADO, M. de F. A. S. O uso de metodologias ativas na pósgraduação em saúde: a experiência do mestrado profissional em saúde da família. Rev Espaço para a Saúde, v. 19, n. 1, p. 187-194, set. 2018.

AQUINO, J. G. A violência escolar e a crise da autoridade docente. Cad Cedes, v. 19, n. 47, 1998.

BAEPLER, P.; WALKER, J. D.; DRIESSEN, M. It's not about seat time: Blending, flipping, and efficiency in active learning classrooms. Computers \& Education, v. 78, p. 227-236, 2014.

BERBEL, N. A. N. Metodologia da problematização: uma alternativa metodológica apropriada para o ensino superior. Semina: Cio Soc.lHum, v. 16, n. 2, ed. esp. p. 9-19, out. 1995.

BRASIL. Conselho Nacional de Educação. Aguardando homologação. Diretrizes curriculares nacionais do curso de graduação em odontologia. Câmara de Educação

RIAEE - Revista Ibero-Americana de Estudos em Educação, Araraquara, v. 15, n. 4, p. 2023-2048, out./dez. 2020. e-ISSN: $1982-5587$. 
Superior. Aprovado em 5 dez. 2018. Disponível em: http://portal.mec.gov.br/docman/abril2019-pdf/111231-pces803-18/file. Acesso: 17 abr. 2020.

BRASIL. Conselho Nacional de Educação. Resolução CNE/CES n. 3, de 19 de fevereiro de 2002. Institui diretrizes curriculares nacionais do curso de graduação em odontologia. Diário Oficial da União, Brasília. Seção 1, p. 10, 4 mar. 2002.

BRASIL. Conselho Nacional de Educação. Resolução CNE/CES n. 3, de 19 de fevereiro de 2002. Institui diretrizes curriculares nacionais do curso de graduação em odontologia. Diário Oficial da União, Brasília. Seção 1, p. 10, 4 mar. 2002.

CARVALHO, S. F. C. de. Júri simulado. A defesa e acusação da odontologia na saúde pública. Rev Espaço para a Saúde, v. 19, n. 1, p. 137-144, set. 2018.

CARVALHO, W. M.; CAWAHISA, P. T.; SCHEIBE, P. C.; BOTELHO, J. N.; TERADA, R. S. S.; ROCHA, N. B.; LOLLI, L. F.; FUJIMAKI, M. Aceitação da utilização de metodologias ativas nos estágios no SUS por discentes da graduação e pós-graduação em Odontologia. Rev. ABENO, Londrina, v.16, n. 1, p. 88-98, jan./mar. 2016

CHAKUR, C. R. de S. L. A desconstrução do construtivismo na educação: crenças e equívocos de professores, autores e críticos [online]. São Paulo: Editora UNESP, 2015. 171 p. ISBN 978-85-6833-448-5. Disponível em: http://books.scielo.org/id/hf4w9. Acesso em: 17 abr. 2020. DOI: https://doi.org/10.7476/9788568334485

Chauí, M. Escritos sobre a universidade. São Paulo: Ed UNESP; 2001.

COSTA, A. R.; ARAÚJO, A. M.; ALMEIDA, L. S. Expectativas académicas em estudantes de engenharia do primeiro ano: Uma análise de clusters. Psicologia, Educação e Cultura, v. 20, n. 1, p. 65-78, 2016. Disponível em: http://hdl.handle.net/11328/1791. Acesso em: 17 abr. 2020 .

COSTA, C. de M. C.; VIEIRA, A. A. S. Metodologias ativas: a experiência do curso MAES. Revista Ibero-Americana de Estudos em Educação, Araraquara, v. 13, n. esp. 1, p. 553 563, maio 2018.

CRUZ, G. V.; PEREIRA, W. R. Diferentes configurações da violência nas relações pedagógicas entre docentes e discentes do ensino superior. Rev Bras Enferm, Brasília, v. 66, n. 2, p. 241-50, mar./abr. 2013.

DEUS, J. M. de et al. Aula centrada no aluno versus aula centrada no professor: desafios para mudança. Rev. bras. educ. med., Rio de Janeiro, v. 38, n. 4, p. 419-426, dez. 2014.

Disponível em: http://www.scielo.br/scielo.php?script=sci_arttext\&pid=S010055022014000400002\&lng=en\&nrm=iso. Acesso em: 23 Mar. 2020. DOI: https://doi.org/10.1590/S0100-55022014000400002.

DOHMS, K. P.; RAMOS, M.; STOBÄUS, C. D.; MOSQUERA, J. J. M. Docente e discente: interinfluências nos processos de ensino e de aprendizagem. Revista Educação por Escrito PUCRS, v. 3, n. 2, dez. 2012. 
FOUCAULT, M. O cuidado com a verdade. In: MOTTA, M. B. (Org.). Ditos e escritos. Volume V. Rio de Janeiro: Forense Universitária, 2004, p. 234-245.

FREITAS, V. da P.; CARVALHO, R. B. de; GOMES, M. J.; FIGUEIREDO, M. C. Mudança no processo ensino-aprendizagem nos cursos de graduação em odontologia com utilização de metodologias ativas de ensino e aprendizagem. RFO, v. 14, n. 2, p. 163-167, maio/ago. 2009. Disponível em: http://seer.upf.br/index.php/rfo/article/view/707. Acesso em: 17 abr. 2020. DOI: https://doi.org/10.5335/rfo.v14i2.707

GEHLEN, S. T.; MALDANER, O. A.; DELIZOICOV, D. Freire e Vygotsky: um diálogo com pesquisas e sua contribuição na educação em ciências. Pro-Posições, Campinas, v. 21, n. 1, p. 129-148, apr. 2010. Disponível em:

http://www.scielo.br/scielo.php?script=sci_arttext\&pid=S010373072010000100009\&lng=en\&nrm=iso. Acesso em: 9 abr. 2020. DOI: https://doi.org/10.1590/S0103-73072010000100009.

GILBOY, M. B.; HEINERICHS, S.; PAZZAGLIA, G. Enhancing Student Engagement Using the Flipped Classroom. Journal of Nutrition Education and Behavior, v. 47, n. 1, p. 109$114,2015$.

GOMES, G.; SOARES, A. B. Inteligência, habilidades sociais e expectativas acadêmicas no desempenho de estudantes universitários. Psicol. Reflex. Crit., Porto Alegre, v. 26, n. 4, p. 780-789, dez. 2013. Disponível em:

http://www.scielo.br/scielo.php?script=sci_arttext\&pid=S0102-

79722013000400019\&lng=en\&nrm=iso. Acesso em: 21 abr. 2020. DOI:

https://doi.org/10.1590/S0102-79722013000400019.

GONÇALVES, A. Y. M.; ROCHA, G. P.; EUCLIDES, K. L. L. C.; FARIAS, T. C. B.; NASCIMENTO, L. S. do. O uso do team-based learning como metodologia de ensino de saúde coletiva na graduação em odontologia. Revista Brasileira de Educação e Saúde, v. 8, n. 1, 2018. Disponível em:

https://www.gvaa.com.br/revista/index.php/REBES/article/view/5452/4946 Acesso: 20 mar. 2020.

GRENWOOD, F.; MULLINS, G.; TOWNSEND, G.; WETHERELL J.; WINNING, T. Evaluation of the performance of graduates from a PBL dental course. In: HERDSA Annual International Conference, 1999, Melbourne. Anais [...]. Melbourne: Higher Education Research and Development Society of Australasia, 1999, 1-13. Disponível em: https://www.researchgate.net/publication/267179870_Evaluation_of_the_performance_of_gra duates_from_a_PBL_dental_course. Acesso em: 17 abr. 2020.

GUIMARÃES, J. C. F. de; SEVERO, E. A.; SERAFIN, V. F.; CAPITANIO, R. P. R. Formação Docente: Uso de Metodologias Ativas Como Processo Inovador de Aprendizagem para o Ensino Superior. In: XVI Mostra de Iniciação Científica, Pós-graduação, Pesquisa e Extensão. Universidade de Caxias do Sul, nov. 2016. Disponível em: http://www.ucs.br/etc/conferencias/index.php/mostraucsppga/xvimostrappga/paper/view/4740 . Acesso em: 17 abr. 2020.

HUNG, H. Flipping the classroom for English language learners to foster active learning. Computer Assisted Language Learning, v. 28, n. 1, p. 81-96, 2015. 
IGUE, É. A.; BARIANI, I. C. D.; MILANESI, P. V. B. Vivência acadêmica e expectativas de universitários ingressantes e concluintes. Psico-USF (Impr.), Itatiba, v. 13, n. 2, p. 155-164, dez. 2008. Disponível em: http://www.scielo.br/scielo.php?script=sci_arttext\&pid=S1413$82712008000200003 \& \operatorname{lng}=e n \& n r m=$ iso. Acesso em:17 abr. 2020. DÖI:

https://doi.org/10.1590/S1413-82712008000200003.

KNOWLES, M. S. The modern practice of adult education: from pedagogy to andragogy. 2. ed. New York: Association Press, 1980.

LAZZARIN, H. C.; NAKAMA, L.; CORDONI JUNIOR, L. O papel do professor na percepção dos alunos de odontologia. Saude soc., São Paulo, v. 16, n. 1, p. 90-101, abr. 2007. Disponível em: http://www.scielo.br/scielo.php?script=sci arttext\&pid=S010412902007000100009\&lng=en\&nrm=iso. Acesso em:17 abr. 2020. DOI: https://doi.org/10.1590/S0104-12902007000100009.

LEAO, D. M. M. Paradigmas Contemporâneos de Educação: Escola Tradicional e Escola Construtivista. Cad. Pesqui., São Paulo, n. 107, p. 187-206, jul. 1999. Disponível em: http://www.scielo.br/scielo.php?script=sci_arttext\&pid=S010015741999000200008\&lng=en\&nrm=iso. Acesso em: 21 abr. 2020. DOI: https://doi.org/10.1590/S0100-15741999000200008.

LEITE, S. A. da S. et al. A afetividade em sala de aula: as condições de ensino e a mediação do professor. Campinas, SP: Papirus, 2004.

LIMA, É. V. Estudantes de medicina em metodologias ativas: desafios da aprendizagem baseada em problemas. Orientador: Ricardo Shoiti Komatsu. 2013. 89 f. Dissertação (Mestrado em Ensino em Saúde) - Faculdade de Medicina de Marília, Marília, SP, 2013. Disponível em:

http://www.famema.br/ensino/metrado_prof/docs/Disserta $\% \mathrm{C} 3 \% \mathrm{~A} 7 \% \mathrm{C} 3 \% \mathrm{~A} 3 \mathrm{o} \% 20 \% \mathrm{C} 3 \% 89$ rica\%20Vernaschi\%20Lima.pdf. Acesso em: 17 abr. 2020.

LIMA, V. V. Competence: different approaches and implications in the training of healthcare professionals. Interface - Comunic., Saúde, Educ., v. 9, n. 17, p. 369-79, mar./ago. 2005.

MACIEL, M. M. S. A.; SILVA, K. B. N. da; MELO, J. G. A. de; SOARES, D. M. Metodologia ativa aplicada ao ensino odontológico: um panorama nacional a partir de um estudo bibliométric. Arch Health Invest, v. 8, n. 2, p. 74-78, 2019. Disponível em: http://dx.doi.org/10.21270/archi.v8i2.3218. Acesso em: 20 abr. 2020.

MACIEL, M. M. S. A.; SILVA, K. B. N. da; MELO, J. G. A. de; SOARES, D. M. Metodologia ativa aplicada ao ensino odontológico: um panorama nacional a partir de um estudo bibliométric. Arch Health Invest, v. 8, n. 2, p. 74-78, 2019. Disponível em: http://dx.doi.org/10.21270/archi.v8i2.3218. Acesso em: 20 abr. 2020.

MANABE, V. M. M. L. et al. Comportamento informacional de ingressantes e concluintes de um curso superior. Encontros Bibli: revista eletrônica de biblioteconomia e ciência da informação, Florianópolis, v. 19, n. 41, p. 41-58, dez. 2014. ISSN 1518-2924. Disponível em: https://periodicos.ufsc.br/index.php/eb/article/view/1518-2924.2014v19n41p41/28287. Acesso em: 21 abr. 2020. DOI: https://doi.org/10.5007/1518-2924.2014v19n41p41 
MARIN, M. J. S. et al. Aspectos das fortalezas e fragilidades no uso das metodologias ativas de aprendizagem. Rev. bras. educ. med., Rio de Janeiro, v. 34, n. 1, p. 13-20, mar. 2010. Disponível em: http://www.scielo.br/scielo.php?script=sci_arttext\&pid=S010055022010000100003\&lng=en\&nrm=iso. Acesso em: 20 abr. 2020. DOI: https://doi.org/10.1590/S0100-55022010000100003

MARTINS, J. V. G.; MENEZES, R. M. T. de; TERÇARIOL, A. A. de L.; GITAHY, R. R. C.; IKESHOJI, E. A. B. O uso de dispositivos móveis na sala de aula: pedagogia de projetos e tecnologias móveis na educação superior. Revista Ibero-Americana de Estudos em Educação, Araraquara, v. 13, n. esp. 1, p. 506-526, maio 2018.

MESQUITA, S. K. da C.; MENESES, R. M. V.; RAMOS, D. K. R. Metodologias ativas de ensino/ aprendizagem: dificuldades de docentes de um curso de enfermagem. Trab. educ. saúde, Rio de Janeiro, v. 14, n. 2, p. 473-486, ago. 2016. Disponível em:http:/www.scielo.br/scielo.php?script=sci_arttext\&pid=S198177462016000200473\&lng=en\&nrm=iso. Acesso em: 25 mar. 2020. DOI: https://doi.org/10.1590/1981-7746-sip00114

MICHAELSEN, L. K.; KNIGHT, A. B.; FINK, L. D. Team-based learning: a transformative use of small Groups. 1. ed. Greenwood Publishing Group, 2002.

MITRE, M. M.; SIQUEIRA-BATISTA, R.; GIRARDI-DEMENDONÇA, J. M.; MORAISPINTO, N. M.; MEIRELLES, C. de A. B.; PINTO-PORTO, C.; MOREIRA, T.; HOFFMANN, L. M. A. Metodologias ativas de ensino-aprendizagem na formação profissional em saúde: debates atuais. Ciên. Saúde Coletiva, v. 13, supl. 2, p. 2133-2144, jan./dez. 2008.

NAGIB, L. de R. C. Relação entre metodologias ativas, ciclo de vida docente e qualificação docente no ensino de graduação em contabilidade. Orientadora: Denise Mendes da Silva. 2018. 134 f. Dissertação (Mestrado em Ciências Contábeis) - Universidade Federal de Uberlândia, Uberlândia, 2018. Disponível em: https://repositorio.ufu.br/handle/123456789/23113. Acesso em: 25 mar. 2020. DOI: http://dx.doi.org/10.14393/ufu.di.2018.1343

NASCIMENTO, L. A.; AZEVEDO, G.; GHIGGI, G. O conceito de amorosidade em Freire e a recuperação do sentido de educar. In: COLÓQUIO INTERNACIONAL PAULO FREIRE, 8., 2013, Recife. Anais [...]. Recife, PE: Centro Paulo Freire - Estudos e Pesquisas, 2013. Disponível em: http://coloquio.paulofreire.org.br/participacao/index.php/coloquio/viiicoloquio/schedConf/presentations. Acesso em: 15 abril, 2020.

NORO L. R. A.; FARIAS-SANTOS, B. C. de S.; SETTE-DE-SOUZA, P. H.; CRUZ, R. K. S.; PINHEIRO, I. A. G.; BORGES, R. E. A. O professor (ainda) no centro do processo ensino aprendizagem em Odontologia. Rev ABENO, v. 15, n. 1, p. 2-11, 2015. Disponível em: http://revabeno.emnuvens.com.br/revab eno/article/view/146. Acesso em: 17 abr. 2020.

O'FLAHERTY, J.; PHILLIPS, C. The use of flipped classrooms in higher education: a scoping review. Internet and Higher Education, v. 25, p. 85-95, 2015. 
OLIVEIRA, S. R. de; CAVALCANTE, A. P.; BARBOZA, L. de A. R. de G.; OLIVEIRA, B. D. R. de; SANTANA, W. A. Metodologias ativas de ensino-aprendizagem na atuação docente em saúde: vivências em uma instituição de ensino superior. Rev Espaço para a Saúde, v. 19, n. 1, p. 205-210, set. 2018 .

OLIVER, R.; KERSTEN, H.; VINKKA-PUHAKKA, H.; ALPASAN, G.; BEARN, D.; CEMA, I. et al. Curriculum structure: principles and strategy. Eur J Dent Educ, v. 12, supl. 1, p. 74-84, 2008.

PAIVA, M. R. F.; PARENTE, J. R. F.; BRANDÃO, I. R.; QUEIROZ, A. H. B. Metodologias ativas de ensino aprendizagem: revisão integrativa. SANARE, Sobral, v.15, n. 2, p.145-153, jun./dez. 2016.

PASSOS, M. L. S.; VIEIRA, A. A. S.; COSTA, C. de M. C. A colaboração facilitando o processo de difusão das experiências vividas no programa professores para o futuro: relatos de experiências. Revista Ibero-Americana de Estudos em Educação, Araraquara, v. 13, n. esp. 1, p. 570-575, maio 2018.

PERRENOUD, P. A prática reflexiva no ofício de professor. Profissionalização e razão pedagógica. Porto Alegre: Artmed Editora, 2002.

PIRES, R. O. M.; BUENO, S. M. V. A problematização como modelo para ensino universitário: uma experiência piloto com alunos do $3^{\circ}$ e $4^{\circ}$ anos do curso de odontologia. Rev ABENO, v. 1, n. 6, p. 54-60, 2006. Disponível em:

http://abeno.org.br/ckfinder/userfiles/files/revista-abeno-2006-1.pdf. Acesso em: 17 abr. 2020.

PIZZI, J. Os desafios da escola pública paranaense na perspectiva do professor. PDE Produções Didático-Pedagógicas. Cadernos PDE, Volume II, 2013-2014. ISBN 978-858015-075-9. Disponível em:

http://www.diaadiaeducacao.pr.gov.br/portals/cadernospde/pdebusca/producoes_pde/2013/20 13_fafipa_cien_pdp_jislaine_pizzi.pdf. Acesso: 01/04/2020.

POLYDORO, S. A. J. O trancamento de matrícula na trajetoria academica do universitario: condições de saida e de retorno a instituição. Orientadora: Elizabeth Nogueira Gomes da Silva Mercuri. 2000. 175 f. Tese (Doutorado) - Universidade Estadual de Campinas, Faculdade de Educação, Campinas, SP. Disponível em:

http://www.repositorio.unicamp.br/handle/REPOSIP/253539. Acesso em: 21 abr. 2020.

POZO, J. I. Aprendizes e mestres, a nova cultura da aprendizagem. Porto Alegre: Artes Médicas, 2002.

MACHADO, A. de B. et al. Práticas inovadoras em metodologias ativas. Florianópolis: Contexto Digital, 2017. 174 p.

LIMA, V. V. et al. Processos educacionais na saúde: ênfase em tecnologias educacionais construtivistas. 2017. 66 p. São Paulo: Ministério da Saúde; Instituto Sírio-Libanês de Ensino e Pesquisa. Caderno do Curso 2017: Facilitadores do PRM/PSUS. 
RAMOS, F. P. A relação professor/aluno e a prática docente contemporânea: um ensaio sobre significados a partir da análise de um episódio dos Simpsons. Revista de Educação, v.14, n. 17, p. 177-186, 2011.

RAMOS, M. N. A Educação profissional pela pedagogia das competências e a superfície dos documentos oficiais. Educação e Sociedade, Campinas, v. 23, n. 80, p. 401-422, 2002.

REUL, M. A.; LIMA, E. D. de; IRINEU, K. do N.; LUCAS, R. S. de C. C.; COSTA, E. M. M. de B.; MADRUGA, R. C. R. Metodologias ativas de ensino aprendizagem na graduação em Odontologia e a contribuição da monitoria - relato de experiência. Rev. ABENO, Londrina, v. 16, n. 2 abr./jun. 2016.

RICH, S. K.; KEIM, R. G.; SHULLER, C. F. Problem-based learning versus a traditional educational methodology: a comparison of preclinical and clinical periodontics performance. J Dental Educ., v. 69, n. 6, p. 649-662, 2005. Disponível em:

http://www.jdentaled.org/content/69/6/649. Acesso em: 17 abr. 2020.

ROCHA, J. S.; DIAS, G. F.; CAMPANHA, N. H.; BALDANI, M. H. O uso da aprendizagem baseada em problemas na Odontologia: uma revisão crítica da literatura. Revista da ABENO, v. 16, n. 1, p. 25-38, 2016.

RODRIGUES, E. U.; CALDAS, M. A. Estudos de casos sobre aborto na metodologia ativa: um debate temático com alunos da graduação em medicina. Rev Espaço para a Saúde, v. 19, n. 1 , p. 115-124, set. 2018 .

ROMERAL, P. A. de A. F. Análise da aplicação de Metodologias Ativas de Ensino no curso de Engenharia de Produção da UTFPR - Campus Londrina. 2019. Monografia (Trabalho de Conclusão de Curso de Engenharia de Produção) - Universidade Tecnológica Federal do Paraná, Londrina, 2019.

RONDON, G. A. de S.; MACIEL, C. M. L. A. Metodologias ativas na educação médica: aprendizagem baseada em problemas, a experiência da Universidade Estadual do Mato Grosso - UNEMAT, sob a perspectiva dos estudantes. Rev Espaço para a Saúde, Curitiba, v. 19, supl. 1, p. 43-51, set. 2018. ISSN 15177130. Disponível em:

https://faculdadespequenoprincipe.edu.br/wp-

content/uploads/2019/01/FPP_SUPLEMENTO_Espa\%C3\%A7oSaude_V-

FINALVALENDO_compressed.pdf. Acesso em: 17 abr. 2019.

SARAIVA, A.M.; SILVA, I. R. G.; LOLLI, L. F.; FUJIMAKI, M.; ALVES, R. das N.; MIGUEL, E. R. A.; MIALCHI, N. da R.; ROCHA, N. B. da. Disciplina interprofissional em saúde: avaliação de discentes de Odontologia. Revista da ABENO, v. 18, n. 4, p. 3-13, 2018. Disponível em: https://revabeno.emnuvens.com.br/revabeno/article/view/598. Acesso em: 17 abr. 2019. DOI: https://doi.org/10.30979/rev.abeno.v18i4.598

SILVA, N. C.; ROSA, M. I. da; SILVA, F. R.; SILVA, D.; GAIDZINSKI, A. Aplicação do tutorial no método ABP, no curso de graduação em medicina da Unesc. Rev Pesqui Extens Saúde, v. 3, n. 1, p. 1-13, 2007.

SILVA, A. N. da; SENNA, M. A.A. de; TEIXEIRA, M. C. B.; LUCIETTO, D. A.; ANDRADE, I. M. de. O uso de metodologia ativa no campo das Ciências Sociais em Saúde:

RIAEE - Revista Ibero-Americana de Estudos em Educação, Araraquara, v. 15, n. 4, p. 2023-2048, out./dez. 2020. e-ISSN: $1982-5587$. 
relato de experiência de produção audiovisual por estudantes. Interface, Botucatu, v. 24, e190231, 2020. Disponível em: https:/www.scielo.br/pdf/icse/v24/1807-5762-icse-24e190231.pdf. Acesso em: 17 abr. 2019. DOI: https://doi.org/10.1590/Interface.190231

SILVA, L. A. A. da et al. Teacher archetypes: perceptions of nursing students. Texto Contexto Enferm, Florianópolis, v. 25, n. 2, e0180014, jul. 2016. Disponível em: http://www.scielo.br/scielo.php?script=sci_arttext\&pid=S010407072016000200316\&lng=en\&nrm=iso. Acesso em: 01 abr. 2020. DOI: https://doi.org/10.1590/0104-07072016000180014.

SOUZA, L. K. de; LOURENCO, E.; SANTOS, M. R. G. dos. Adaptação à universidade em estudantes ingressantes na graduação em psicologia. Psicol. educ., São Paulo, n. 42, p. 35-48, jun. 2016. Disponível em http://pepsic.bvsalud.org/scielo.php?script=sci_arttext\&pid=S141469752016000100004\&lng=pt\&nrm=iso. Acesso em: 26 mar. 2020. DOI: http://dx.doi.org/10.5935/2175-3520.20150023.

TAVARES, C. R. O conceito holístico de competência: concepção e uso na formação profissional e gestão nas organizações. In: Anais da Academia Pernambucana de Ciência Agronômica, v. 15, n. 2, p. 37-40, 2018. Crônicas.

THAMMASITBOON, K.; SUKOTJO, C.; HOWELL, H.; KARIMBUX, N. Problem-based learning at the Harvard School of Dental Medicine: self-assessment of performance in postdoctoral training. J Dent. Educ., v. 71, n. 8, p. 1080-1089, 2007. Disponível em: http://http://www.jdentaled.org/content/71/8/1080. Acesso em: 17 abr. 2020.

TORRES, V.; SAMPAIO, C. A.; CALDEIRA, A. P. Ingressantes de cursos médicos e a percepção sobre a transição para uma aprendizagem ativa. Interface, Botucatu, v. 23, e1700471, 2019. Disponível em:http://www.scielo.br/scielo.php?script=sci_arttext\&pid=S141432832019000100203\&lng=en\&nrm=iso. Acesso em: 25 mar. 2020. DOI: https://doi.org/10.1590/interface.170471.

VERAS, R. da S.; FERREIRA, S. P. A. A afetividade na relação professor-aluno e suas implicações na aprendizagem, em contexto universitário. Educ. rev., Curitiba, n. 38, p. 219235, dez. 2010. Disponível em:

http://www.scielo.br/scielo.php?script=sci_arttext\&pid=S010440602010000300015\&lng=en\&nrm=iso. Acesso em: 16 abr. 2020. https://doi.org/10.1590/S0104-40602010000300015.

VINCI, C. F. R. G. A problematização e as pesquisas educacionais: sobre um gesto analítico foucaultiano. Filosofia e Educação, Campinas, v. 7, n. 2, p. 195-219, jun./set, 2015. ISSN 1984-9605. 


\section{Como referenciar este artigo}

GONTIJO, L. P. T.; HERVAL, Á. M.; CARCERERI, D. L.; FREITAS, S. F. T. de. Aceitabilidade das metodologias ativas de ensino-aprendizagem entre discentes de odontologia. Revista Ibero-Americana de Estudos em Educação, Araraquara, v. 15, n. 4, p. 2023-2048, out./dez. 2020 https://doi.org/10.21723/riaee.v15i4.13693

e-ISSN: $\quad$ 1982-5587.

DOI:

Submetido em: 14/01/2020

Revisões requeridas em: 25/03/2020

Aprovado em: $14 / 06 / 2020$

Publicado em: 30/08/2020 